\title{
Perfil socioeconômico-demográfico do beneficiário do Instituto Nacional do Seguro Social aposentado por invalidez e suas causas, no Estado da Paraíba, no quinquênio 2007-2011
}

\author{
Talianne Rodrigues Santos* \\ Windsor Ramos da Silva Júnior** \\ Inácia Sátiro Xavier de França ${ }^{\star \star *}$ \\ Alessandro Leite Cavalcanti ${ }^{\star \star \star \star}$ \\ Maria das Graças Melo Fernandes ${ }^{\star \star \star \star *}$
}

\begin{abstract}
Aposentadoria por invalidez provoca um impacto limitante no crescimento da força de trabalho. Este artigo procura traçar o perfil socioeconômico-demográfico do beneficiário aposentado por invalidez, na Paraíba, no quinquênio 2007-2011 e verificar a proporção de benefícios concedidos e suas causas. Para tanto, foi realizada uma pesquisa observacional, descritiva, com dados secundários, a partir de um formulário construído para coleta de dados, contendo as seguintes variáveis: ano em que o benefício foi concedido; motivo do afastamento segundo o Código Internacional de Doenças (10 ${ }^{a}$ Revisão); faixa etária, sexo e faixa salarial do aposentado após a invalidez; tempo de contribuição ao INSS antes da aposentadoria; e forma de filiação (desempregado, segurado especial, autônomo, facultativo, empregado doméstico e trabalhador avulso). Para análise, foi utilizado o software Statistical Package for Social Sciences (SPSS), versão 20.0. Do total de 13.537 beneficiários por invalidez, 62,8\% estavam na faixa de 40 a 59 anos, 64\% eram do sexo masculino, 63\% possuíam uma média salarial entre um e dois salários mínimos, $28,3 \%$ dos benefícios foram concedidos a pessoas desempregadas e 25,3\% das concessões deveram-se a doenças circulatórias. Espera-se que este estudo seja propulsor de outros estudos no Estado da Paraíba, pois a mensuração de indicadores é necessária para que se possa intervir visando a redução das aposentadorias por invalidez.
\end{abstract}

Palavras-chave: Benefícios de aposentadoria. Benefícios do seguro. Invalidez.

\footnotetext{
* Enfermeira, especialista em Saúde da Família, mestre em Saúde Pública pela Universidade Estadual da Paraíba - UEPB (taliannerodrigues@hotmail.com).

${ }^{* *}$ Fisioterapeuta, especialista em Fisioterapia Manual, mestrando em Saúde Pública pela Universidade Estadual da Paraíba - UEPB (windsor.jr@gmail.com).

*** Enfermeira, doutora em Enfermagem, professora do Departamento de Enfermagem da Universidade Estadual da Paraíba - UEPB.

**** Odontólogo, doutor em Estomatologia, professor do Departamento de Odontologia da Universidade Estadual da Paraíba - UEPB (dralessandro@ibest.com.br).

***** Enfermeira, doutora em Sociologia e em Ciências da Saúde, professora do Departamento de Enfermagem da Universidade Federal da Paraíba (graacafernandes@hotmail.com).
} 


\section{Introdução}

O Regime Brasileiro de Previdência Social - RBPS está atribuído às disposições elencadas na Lei n. 8.213, de 24 de julho de 1991, que estabelece os princípios dos planos e benefícios concedidos pela Previdência Social. A autarquia responsável pela gerência do seguro social é o Instituto Nacional do Seguro Social - INSS.

As contribuições ao sistema previdenciário são realizadas compulsória e automaticamente pelos empregados e empregadores e têm a finalidade de auxiliar financeiramente a população presente, ou não, no mercado de trabalho formal, seja por doença ou invalidez, seja por idade avançada.

Aposentadoria por invalidez é o benefício concedido aos trabalhadores que, por doença ou acidente, sejam considerados inaptos para atividades laborais que lhes garantam a sobrevivência. A solicitação da aposentadoria é deferida se o início da incapacidade, constatada durante o exame médico-pericial, for posterior à realização do período de carência de 12 contribuições mensais, afora as circunstâncias que desobrigam a carência que são previstas na legislação, como acidente de qualquer natureza, doenças incapacitantes especificadas pelo Ministério da Saúde e Previdência Social ou o trabalhador rural.

O trabalhador rural necessita provar apenas trabalho rural nos 12 meses antecedentes à invalidez, configurando-se como forma de filiação o segurado especial. Estão incluídos nessa categoria cônjuges, companheiros e filhos maiores de 16 anos que trabalham com a família em atividade rural. Também são considerados segurados especiais o pescador artesanal e o índio que exerce atividade rural e seus familiares.

Normalmente, o seguro inicial é o benefício auxílio-doença, sendo que a cada seis meses há uma reavaliação pela perícia médica e, não tendo condições de voltar ao trabalho, será concedida a aposentadoria por invalidez.

De acordo com o Anuário Estatístico da Previdência Social - AEPS (2010), em 2008, o INSS gerou um total de 1.016.250 aposentadorias no Brasil, das quais 195.451 (em torno de 19,2\%) foram concedidas por invalidez, o que gerou em custos uma média de $R \$ 152.390 .000$ para o sistema previdenciário. Na Paraíba, no mesmo período, das 21.398 aposentadorias, 3.338 $(15,5 \%)$ foram por invalidez, equivalendo a uma despesa de $\mathrm{R} \$ 11.006 .000$.

A diminuição da população trabalhadora no mercado acarreta inúmeras repercussões econômicas e sociais, pois os indivíduos em idade produtiva passam a depender de um benefício, inclusive, podendo gerar redução da renda familiar.

Um estudo realizado no semiárido brasileiro em 2001, por Sandi e Heringer (2001), no qual está incluído o Estado da Paraíba, observa que cada aposentadoria beneficia o próprio aposentado e mais 2,5 pessoas, em média, chegando a atingir, dessa forma, em torno de 9,1 milhões de habitantes direta e indiretamente, o que corresponde a cerca de $47 \%$ da população total da região. A relação na área rural ainda é mais significativa, alcançando $78,5 \%$.

Segundo tal estudo, as doenças ocupacionais, comuns do processo de industrialização e urbanização, e o envelhecimento populacional acarretam a ampliação de doenças crônicas não transmissíveis DCNTs. Ressalta-se nos estudos a evidência da DCNT como a principal causa da aposentadoria por invalidez, destacando-se as doenças do aparelho circulatório, doenças osteomusculares, transtornos mentais/ comportamentais e neoplasias. Portanto, esse grupo de doenças é responsável pelo crescimento de uso e custos nos serviços de saúde, sendo considerado pela Organização Mundial de Saúde - OMS um importante problema de saúde pública.

A promoção, prevenção e reabilitação dos indivíduos são fatores essenciais para redução nas taxas de incapacidades laborais. É importante observar a necessidade da interdisciplinaridade entre o Sistema Único de Saúde e a Previdência Social, principalmente na criação de políticas públicas para reinserção e/ou readaptação do trabalhador no mercado, visando melhorar a qualidade de vida do mesmo e diminuir a necessidade de aposentadoria. 
Assim, diante da importância desses fatos e da presença de poucos estudos recentes na Paraíba, pretende-se analisar as motivações de concessão de benefícios sociais decorrentes de incapacidade por doença, especificamente a aposentadoria por invalidez, tendo como objetivo descrever o perfil socioeconômico-demográfico do beneficiário aposentado por invalidez, verificar a proporção de benefícios e aposentadorias concedidas e analisar as causas de aposentadoria por invalidez segundo os códigos de ocorrência mais frequente na Classificação Internacional de Doenças - 10 ${ }^{\text {a }}$ Revisão (CID-10), no período de 2007 a 2011.

\section{Metodologia}

Este estudo é observacional e descritivo, de corte transversal retrospectivo, e de abordagem quantitativa, utilizando dados secundários. Os dados foram obtidos a partir da Coordenação Geral da primeira gerência do Instituto Nacional do Seguro Social (INSS) em Campina Grande, em formato digital, por meio de consulta de informações dos Anuários Estatísticos da Previdência Social (AEPS) disponíveis no sítio <http://www.mpas.gov.br/conteudoDinamico.php?id=423> e de pedido formal de dados do Sistema Único de Informações de Benefícios (Suibe), para o Estado da Paraíba, no quinquênio 2007-2011, contendo os benefícios de aposentadoria concedidos por invalidez previdenciária "B32". Esses registros excluem as aposentadorias por invalidez inclusas no código "B92", denominadas aposentadorias acidentárias.

As variáveis utilizadas para o estudo foram: Classificação Estatística Internacional de Doenças e Problemas Relacionados à Saúde em sua décima revisão (CID-10), versão 2008 (OMS, 2008); faixa salarial do aposentado após a invalidez; tempo de contribuição antes da aposentadoria; forma de filiação (desempregado, segurado especial, autônomo, facultativo, empregado doméstico e trabalhador avulso); faixa etária; e sexo.

Os dados foram analisados estatisticamente de forma descritiva. Foi adotado um nível de significância de 5\% por meio do software Statistical Package for Social Sciences (SPSS) versão 20.0.

O presente estudo teve aprovação do Comitê de Ética e Pesquisa da Universidade Estadual da Paraíba - UEPB sob o CAAE n. 0002.0.133.000-12.

\section{Resultados}

De acordo com os dados coletados na pesquisa, constatou-se que, no Brasil, entre 2007 e 2011, foram concedidas 881.591 aposentadorias por invalidez (espécie B32), das quais 13.537 referem-se ao Estado da Paraíba, o que corresponde a $1,5 \%$ do total, constituindo a amostra do estudo.

A Tabela 1 apresenta o total das aposentadorias por invalidez na Paraíba, segundo características socioeconômicas e demográficas dos beneficiários.

De acordo com os dados da Tabela 1, durante o período do estudo, foram concedidas em média 2.707 aposentadorias por ano (desvio-padrão de 381,9). Quanto às características socioeconômicas e demográficas para o total dos aposentados por invalidez, verificou-se predominância de homens, com 8.673 concessões (64\%), faixa etária entre 40 e 59 anos (8.486, ou 62,8\%), forma de filiação no momento da aposentadoria como desempregado (3.836, ou $28,3 \%$ ) e segurado especial (3.513, ou $26,0 \%$ ), embora, ao longo dos anos, tenham ocorrido mudanças na forma de filiação do segurado, o que pode ser observado no Gráfico 1.

Na maior parte das concessões -11.751 (87\%) - os beneficiários tinham 15 anos ou menos de contribuição junto ao INSS (Tabela 1). Em relação ao salário que o segurado começou a receber após a aposentadoria, verifica-se que, até 2008 , o benefício da maior parte dos segurados era entre $1 \mathrm{e}$ 2 salários mínimos, passando, a partir de 2009, para um salário mínimo (Gráfico 2).

Outra variável estudada foi a causa mais frequente de aposentadoria por invalidez, segundo a CID-10, no decorrer dos anos (Tabela 2).

Dos 13.537 casos analisados de aposentadorias por invalidez, $4.162(30,7 \%)$ não tinham informação sobre seus capítulos da CID-10. Na Tabela 2, que apresenta esses 
TABELA 1

Distribuição dos aposentados por invalidez, segundo características socioeconômicas e demográficas Estado da Paraíba - 2007-2011

\begin{tabular}{|c|c|c|c|c|c|c|c|c|c|c|c|c|}
\hline \multirow{2}{*}{$\begin{array}{l}\text { Características socioeconômicas } \\
\text { e demográficas }\end{array}$} & \multicolumn{2}{|c|}{2007} & \multicolumn{2}{|c|}{2008} & \multicolumn{2}{|c|}{2009} & \multicolumn{2}{|c|}{2010} & \multicolumn{2}{|c|}{2011} & \multicolumn{2}{|c|}{ Total } \\
\hline & $\begin{array}{l}\text { N. } \\
\text { abs. }\end{array}$ & $\%$ & $\begin{array}{l}\text { N. } \\
\text { abs. }\end{array}$ & $\%$ & $\begin{array}{l}\text { N. } \\
\text { abs. }\end{array}$ & $\%$ & $\begin{array}{l}\text { N. } \\
\text { abs. }\end{array}$ & $\%$ & $\begin{array}{l}\text { N. } \\
\text { abs. }\end{array}$ & $\%$ & N. abs. & $\%$ \\
\hline Aposentadorias concedidas & 2.162 & 16,0 & 2.704 & 20,0 & 2.657 & 19,6 & 3.235 & 23,9 & 2.779 & 20,5 & 13.537 & 100,0 \\
\hline \multicolumn{13}{|l|}{ Sexo } \\
\hline Homens & 1.406 & 65,0 & 1.742 & 64,4 & 1.743 & 65,6 & 2.023 & 62,5 & 1.759 & 63,3 & 8.673 & 64,0 \\
\hline Mulheres & 756 & 35,0 & 962 & 35,6 & 914 & 34,4 & 1.212 & 37,5 & 1.020 & 36,7 & 4.864 & 36,0 \\
\hline \multicolumn{13}{|l|}{ Faixa Etária } \\
\hline Até 19 anos & 59 & 2,7 & 55 & 2,0 & 49 & 1,8 & 145 & 4,5 & 38 & 1,4 & 346 & 2,5 \\
\hline $20-29$ anos & 78 & 3,6 & 93 & 3,4 & 90 & 3,4 & 95 & 2,9 & 107 & 3,9 & 463 & 3,4 \\
\hline 30-39 anos & 256 & 11,8 & 312 & 11,6 & 312 & 11,6 & 326 & 10,0 & 328 & 11,7 & 1.534 & 11,3 \\
\hline 40-49 anos & 480 & 22,2 & 628 & 23,3 & 584 & 22,0 & 746 & 23,1 & 663 & 23,9 & 3.101 & 23,0 \\
\hline $50-59$ anos & 837 & 38,7 & 1.095 & 40,5 & 1.057 & 39,8 & 1.277 & 39,5 & 1.119 & 40,3 & 5.385 & 39,8 \\
\hline 60 anos e mais & 452 & 21,0 & 521 & 19,3 & 565 & 21,3 & 646 & 20,0 & 524 & 18,8 & 2.708 & 20,0 \\
\hline \multicolumn{13}{|l|}{ Forma de filiação junto ao INSS } \\
\hline Desempregado & 647 & 29,9 & 878 & 32,5 & 753 & 28,3 & 872 & 27,0 & 686 & 24,7 & 3.836 & 28,3 \\
\hline Segurado especial & 536 & 24,7 & 640 & 23,7 & 664 & 25,0 & 853 & 26,4 & 820 & 29,5 & 3.513 & 26,0 \\
\hline Autônomo & 412 & 19,1 & 497 & 18,4 & 485 & 18,3 & 642 & 19,8 & 468 & 16,8 & 2.504 & 18,4 \\
\hline Empregado & 285 & 13,2 & 358 & 13,2 & 404 & 15,2 & 479 & 14,8 & 515 & 18,5 & 2.041 & 15,0 \\
\hline Facultativo & 192 & 8,9 & 200 & 7,4 & 245 & 9,2 & 285 & 8,8 & 199 & 7,2 & 1.121 & 8,3 \\
\hline Doméstico & 50 & 2,3 & 73 & 2,7 & 76 & 2,9 & 101 & 3,1 & 89 & 3,2 & 389 & 3,0 \\
\hline Outros & 40 & 1,9 & 58 & 2,1 & 30 & 1,1 & 3 & 0,1 & 2 & 0,1 & 133 & 1,0 \\
\hline \multicolumn{13}{|l|}{ Tempo de contribuição } \\
\hline 15 anos & 1.815 & 84,0 & 2.348 & 86,8 & 2.305 & 86,7 & 2.866 & 88,6 & 2.417 & 87,0 & 11.751 & 87,0 \\
\hline $16-20$ anos & 150 & 6,9 & 186 & 6,9 & 190 & 7,2 & 190 & 5,9 & 164 & 5,9 & 880 & 6,5 \\
\hline $21-25$ anos & 96 & 4,5 & 81 & 3,0 & 98 & 3,7 & 119 & 3,7 & 118 & 4,2 & 512 & 3,8 \\
\hline 26-30 anos & 31 & 1,4 & 47 & 1,7 & 37 & 1,4 & 43 & 1,3 & 64 & 2,3 & 222 & 1,6 \\
\hline $31-35$ anos & 14 & 0,6 & 10 & 0,4 & 15 & 0,6 & 10 & 0,3 & 14 & 0,5 & 63 & 0,4 \\
\hline 36-39 anos & 3 & 0,1 & 2 & 0,1 & 1 & 0,0 & 4 & 0,1 & 2 & 0,1 & 12 & 0,0 \\
\hline 40 anos e mais & 53 & 2,5 & 30 & 1,1 & 11 & 0,4 & 3 & 0,1 & 0 & 0,0 & 97 & 0,7 \\
\hline
\end{tabular}

Faixa salarial (em salários mínimos)

\begin{tabular}{lrrrrrrrrrrrr} 
1 SM & 12 & 1,4 & 9 & 0,9 & 1.658 & 62,3 & 2.025 & 62,6 & 1.784 & 64,2 & 5.488 & 52,0 \\
1-2 SM & 462 & 53,9 & 578 & 54,8 & 595 & 22,3 & 763 & 23,6 & 651 & 23,4 & 3.049 & 28,9 \\
2-3 SM & 163 & 19,1 & 214 & 20,3 & 188 & 7,1 & 221 & 6,8 & 173 & 6,2 & 959 & 9,0 \\
3-4 SM & 77 & 9,0 & 109 & 10,4 & 109 & 4,1 & 106 & 3,3 & 66 & 2,4 & 467 & 4,4 \\
4-5 SM & 46 & 5,4 & 50 & 4,8 & 44 & 1,7 & 53 & 1,6 & 58 & 2,1 & 251 & 2,4 \\
5-6 SM & 39 & 4,6 & 52 & 4,9 & 31 & 1,2 & 42 & 1,3 & 31 & 1,1 & 195 & 1,8 \\
6-7 SM & 35 & 4,1 & 30 & 2,9 & 23 & 0,9 & 19 & 0,6 & 14 & 0,5 & 121 & 1,1 \\
7-8 SM & 16 & 1,9 & 8 & 0,8 & 7 & 0,3 & 3 & 0,1 & 2 & 0,1 & 36 & 0,3 \\
8-9 SM & 5 & 0,6 & 2 & 0,2 & 2 & 0,1 & 3 & 0,1 & 0 & 0,0 & 12 & 0,1 \\
\hline
\end{tabular}

Fonte: Sistema Único de Informações de Benefícios - Suibe 2012.

dados, a porcentagem foi calculada sobre os casos que possuíam informações sobre os capítulos da CID-10.

Dos 9.375 casos cujos capítulos da CID10 estavam informados, $2.370(25,3 \%)$ referiam-se às doenças do aparelho circulatório, que foram a principal causa de aposentadoria por invalidez no período estudado, trazendo como as principais causas do capítulo as sequelas de doenças cerebrovasculares, as doenças cardíacas hipertensivas e insuficiência e isquemia cardíaca. Em seguida, com 


\section{GRÁFICO 1}

Distribuição das aposentadorias por invalidez, segundo forma de filiação ao INSS antes da concessão do benefício

Estado da Paraíba - 2007-2011

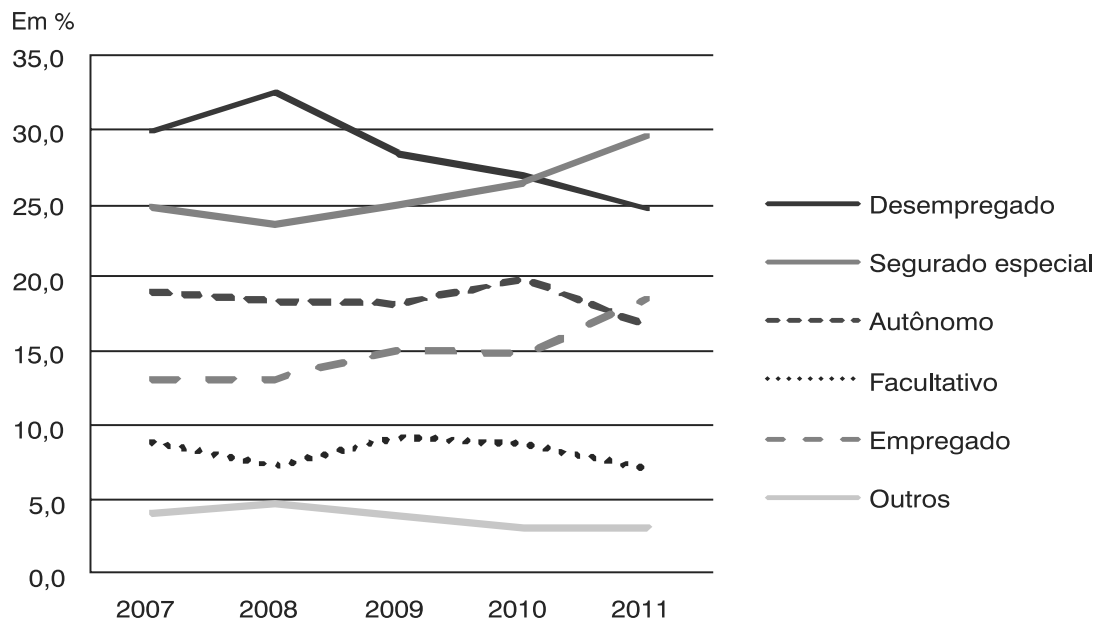

Fonte: Sistema Único de Informações de Benefícios - Suibe 2012.

GRÁFICO 2

Distribuição das aposentadorias por invalidez, segundo faixa salarial após o benefício concedido Estado da Paraíba - 2007-2011

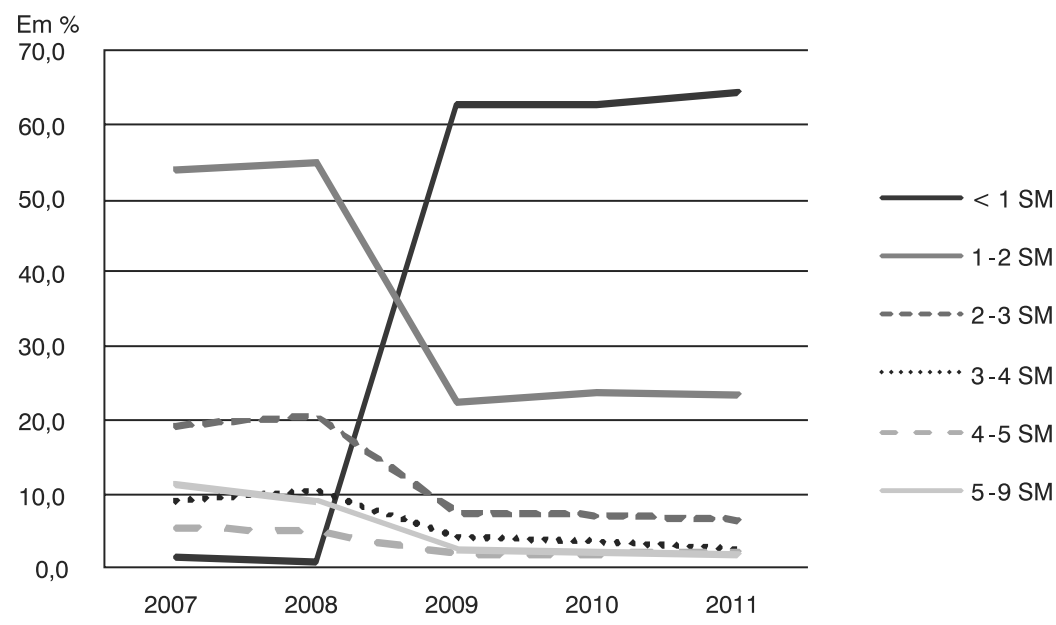

Fonte: Sistema Único de Informações de Benefícios - Suibe 2012.

$1.523(16,2 \%)$ casos de aposentadorias, vêm as doenças osteomusculares, apresentando como as principais doenças do capítulo os transtornos de discos intervertebrais e artroses. As neoplasias, com 1.206 (13\%) casos, ocuparam o terceiro lugar das doenças que mais aposentaram entre 2007 e 2011, em destaque o câncer de mama e o de próstata como as principais causas do capítulo. A partir do Gráfico 3, é possível observar o comportamento do número de casos de aposentadoria por invalidez, durante o período analisado, segundo os cinco capítulos da CID-10 mais informados. 
TABELA 2

Distribuição das aposentadorias por invalidez, segundo os capítulos da CID-10 Estado da Paraíba - 2007-2011

\begin{tabular}{|c|c|c|c|c|c|c|c|c|c|c|c|c|}
\hline \multirow[b]{2}{*}{ Capítulos da CID-10 } & \multicolumn{2}{|c|}{2007} & \multicolumn{2}{|c|}{2008} & \multicolumn{2}{|c|}{2009} & \multicolumn{2}{|c|}{2010} & \multicolumn{2}{|c|}{2011} & \multicolumn{2}{|c|}{ Total } \\
\hline & $\begin{array}{l}\text { N. } \\
\text { abs. }\end{array}$ & $\%$ & $\begin{array}{l}\text { N. } \\
\text { abs. }\end{array}$ & $\%$ & $\begin{array}{l}\text { N. } \\
\text { abs. }\end{array}$ & $\%$ & $\begin{array}{l}\text { N. } \\
\text { abs. }\end{array}$ & $\%$ & $\begin{array}{l}\text { N. } \\
\text { abs. }\end{array}$ & $\%$ & $\begin{array}{l}\text { N. } \\
\text { abs. }\end{array}$ & $\%$ \\
\hline $\begin{array}{l}\text { Capítulo IX - Doenças do aparelho } \\
\text { circulatório (100-199) }\end{array}$ & 416 & 26,4 & 558 & 27,5 & 442 & 24,2 & 525 & 24,3 & 429 & 24,0 & 2.370 & 25,3 \\
\hline $\begin{array}{l}\text { Capítulo XIII - Doenças do sistema } \\
\text { osteomuscular e do tecido } \\
\text { conjuntivo (M00-M99) }\end{array}$ & 224 & 14,2 & 298 & 14,7 & 305 & 16,7 & 394 & 18,3 & 302 & 16,9 & 1.523 & 16,2 \\
\hline $\begin{array}{l}\text { Capítulo II - Neoplasias [tumores] } \\
\text { (C00-D48) }\end{array}$ & 217 & 13,8 & 245 & 12,1 & 232 & 12,7 & 270 & 12,5 & 242 & 13,5 & 1.206 & 13,0 \\
\hline $\begin{array}{l}\text { Capítulo V - Transtornos mentais e } \\
\text { comportamentais (F00-F99) }\end{array}$ & 169 & 10,7 & 215 & 10,6 & 140 & 7,7 & 255 & 11,8 & 163 & 9,1 & 942 & 10,0 \\
\hline $\begin{array}{l}\text { Capítulo XIX - Lesões, } \\
\text { envenenamento e algumas outras } \\
\text { conseqüências de causas externas } \\
\text { (S00-T98) }\end{array}$ & 119 & 7,5 & 162 & 8,0 & 156 & 8,6 & 157 & 7,3 & 173 & 9,7 & 767 & 8,2 \\
\hline $\begin{array}{l}\text { Capítulo VII - Doenças do olho e } \\
\text { anexos (H00-H59) }\end{array}$ & 129 & 8,2 & 151 & 7,5 & 142 & 7,8 & 130 & 6,0 & 106 & 5,9 & 658 & 7,0 \\
\hline $\begin{array}{l}\text { Capítulo VI - Doenças do sistema } \\
\text { nervoso (G00-G99) }\end{array}$ & 94 & 6,0 & 138 & 6,8 & 137 & 7,5 & 136 & 6,3 & 108 & 6,0 & 613 & 6,5 \\
\hline $\begin{array}{l}\text { Capítulo XIV - Doenças do aparelho } \\
\text { geniturinário (N00-N99) }\end{array}$ & 55 & 3,5 & 57 & 2,8 & 63 & 3,5 & 65 & 3,0 & 58 & 3,2 & 298 & 3,2 \\
\hline $\begin{array}{l}\text { Capítulo IV - Doenças endócrinas, } \\
\text { nutricionais e metabólicas (E00-E90) }\end{array}$ & 40 & 2,5 & 55 & 2,7 & 72 & 3,9 & 66 & 3,1 & 64 & 3,6 & 297 & 3,2 \\
\hline $\begin{array}{l}\text { Capítulo I - Algumas doenças } \\
\text { infecciosas e parasitárias (A00-B99) }\end{array}$ & 51 & 3,2 & 68 & 3,4 & 55 & 3,0 & 58 & 2,7 & 58 & 3,2 & 290 & 3,1 \\
\hline $\begin{array}{l}\text { Capítulo X - Doenças do aparelho } \\
\text { respiratório (J00-J99) }\end{array}$ & 26 & 1,5 & 34 & 1,7 & 43 & 2,4 & 45 & 2,1 & 33 & 1,8 & 181 & 2,0 \\
\hline $\begin{array}{l}\text { Capítulo XI - Doenças do aparelho } \\
\text { digestivo (K00-K93) }\end{array}$ & 19 & 1,2 & 25 & 1,2 & 17 & 0,9 & 35 & 1,6 & 25 & 1,4 & 121 & 1,3 \\
\hline Outros & 19 & 1,3 & 23 & 1,0 & 19 & 1,1 & 21 & 1,0 & 27 & 1,5 & 109 & 1,0 \\
\hline Total & 1.578 & 100,0 & 2.029 & 100,0 & 1.823 & 100,0 & 2.157 & 100,0 & 1.788 & 100,0 & 9.375 & 10,00 \\
\hline Não informados & 584 & & 675 & & 834 & & 1.078 & & 991 & & 4.162 & \\
\hline
\end{tabular}

Fonte: Sistema Único de Informações de Benefícios - Suibe 2012.

GRÁFICO 3

Aposentadorias por invalidez, segundo as cinco primeiras causas (capítulos da CID-10) Estado da Paraíba - 2007-2011
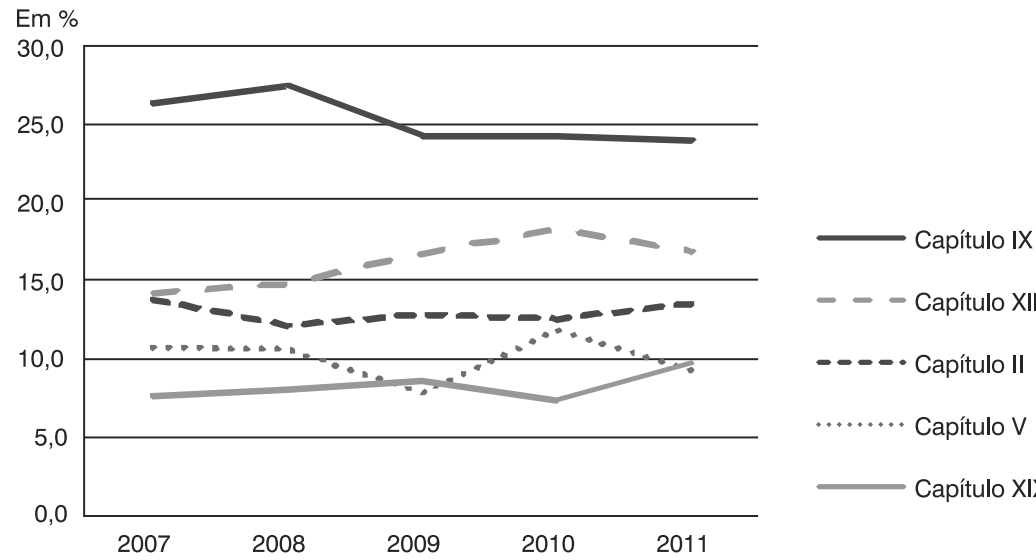
- - Capítulo XIII $---\cdot$ Capítulo II ........ Capítulo V Capítulo XIX

Fonte: Sistema Único de Informações de Benefícios - Suibe 2012. 


\section{Discussão}

Os dados da presente pesquisa devem ser interpretados para a população estudada, pois são informações referentes aos trabalhadores segurados pelo INSS e às pessoas beneficiárias de aposentadoria que não precisam de carência, portanto, não abarcando todos os trabalhadores do Brasil.

Outras restrições do estudo são a insuficiência de alguns dados relativos aos denominadores e a subnotificação de outros, interferindo nos resultados, principalmente pela alimentação do banco de dados, podendo ser explicada pelo fato de que os responsáveis talvez possam considerar a interação com o sistema como burocrática e desvinculada de sua própria atividade, contribuindo para a baixa qualidade das informações. A dependência da concessão de benefícios em relação à política do Ministério da Previdência Social pode variar de um governo para outro, sendo mais um fator pelo qual os dados podem sofrer influências pela variabilidade das avaliações realizadas pelos peritos.

Outro entrave é que os estudos no país, em geral, são realizados com populações de trabalhadores que estão vulneráveis ao "efeito trabalhador sadio", no qual afirma ser um tipo de viés de seleção em estudos epidemiológicos que tendem a subestimar a ocorrência dos problemas de saúde, pois os trabalhadores em atividade seriam mais saudáveis e aptos para o trabalho do que os indivíduos suscetíveis fora da força de trabalho, devido a problemas de saúde. Este fato poderia subestimar os efeitos da exposição. Ou seja, as informações sobre morbimortalidade dos trabalhadores são limitadas, fragmentadas e heterogêneas.

A divergência encontrada no estudo quanto ao sexo do aposentado por invalidez na Paraíba, no período 2007-2011, pode ser explicada, como já mencionado anteriormente, pela diferença da fonte de dados, sendo que a maioria dos estudos epidemiológicos aponta o perfil de trabalhadores em instituições privadas ou ambulatoriais, onde a predominância é do público feminino. Ressalva-se que o presente estudo analisa a população ligada à Previdência
Social, assemelhando-se à pesquisa de Gomes, Fígoli e Ribeiro (2010). Além disso, os homens tendem a resistir à procura de tratamento e reabilitação, permanecendo por mais tempo na atividade, mesmo com dor e/ou desconforto, podendo, inclusive, gerar uma situação posterior não reversível à recuperação.

Outra explicação para a disparidade da amostra é que, apesar do crescimento da inserção feminina no mercado de trabalho durante as últimas décadas e da redução da diferença salarial entre os sexos, ainda há grande divergência no mercado de trabalho e nas atividades domésticas.

Em consequência da presença dos filhos e do cuidado com a família, as oportunidades de emprego para as mulheres diminuem e, por muitas vezes, as direcionam para serviços de pior qualidade, oferecendo jornadas de trabalho mais reduzidas e menor proteção previdenciária. Outro fato que se deve recordar é que o Estado da Paraíba ainda é envolto por muitos preconceitos em relação ao sexo feminino, sendo ainda observados alguns comportamentos de uma sociedade patriarcal.

Em relação à forma de filiação, a maior quantidade das aposentadorias concedidas por invalidez $(28,3 \%)$ correspondeu às pessoas que não possuíam emprego anteriormente, vindo em seguida o segurado especial (26,0\%), o que traz grande prejuízo econômico para o país, pois as pessoas desempregadas raramente contribuem para o INSS, assim como o aposentado por invalidez na categoria de segurado especial, que, como explicado anteriormente, dependendo do caso, não necessita contribuir para se aposentar.

A previdência brasileira baseia-se no modelo de repartição simples, cuja lógica pressupõe um equilíbrio coletivo: as contribuições previdenciárias pagas pelos trabalhadores ativos destinam-se a cobrir os gastos com os benefícios dos inativos. O regime de repartição, em tese, seria sustentável pelo maior número de futuros contribuintes, responsáveis pelas aposentadorias e pensões dos atuais contribuintes. Na prática, o aumento expressivo da produtividade da mão de obra faz com que essa 
premissa esteja incorreta mesmo diante de um quadro de crescimento econômico sustentável, quanto mais diante de períodos de baixo ou nenhum crescimento econômico.

Além disso, a transição demográfica em países como o Brasil tende a tornar mais crítica a desproporção entre contribuintes e beneficiários da previdência social. Com o aumento do desemprego, a diminuição do montante salarial dos contribuintes e o pouco tempo de contribuição, menos trabaIhadores formais terão que sustentar mais aposentados por longo período.

No presente estudo verificou-se que, ao longo dos anos, vem diminuindo o quantitativo de desempregados como forma de filiação junto ao INSS; em consequência, o empregado tende a ascender, melhorando a estabilidade e segurança do trabalhador $e$ alcançando uma melhor qualidade de vida.

Em relação ao valor da aposentadoria após o benefício, pode-se concluir que, quanto maior o valor mensal inicial, menor é a quantidade de segurados contida neste grupo. Este fato possivelmente é atribuído ao fato de a maior parte da população segurada contribuir somente sobre o valor mínimo de contribuição, o que está de acordo com o contexto de baixos salários em que está inserida a maioria dos trabalhadores brasileiros.

Entretanto, destaca-se que o valor do salário mínimo não garante os direitos de cidadania e de justiça social. A baixa faixa salarial da aposentadoria, em consequência da faixa salarial mensal dos contribuintes encontrada na amostra, pode estar associada a piores condições de trabalho e comumente tem sido correlacionada com o aparecimento de incapacidades.

No presente estudo ainda é possível perceber que há uma relação diretamente proporcional entre o aumento da faixa etária e a quantidade de aposentadorias concedidas por invalidez. É notória a diferença de aposentadorias por idade na faixa dos 50 a 59 anos, que é o grupo etário com maior número de beneficiários. No segmento com mais de 60 anos, observa-se uma diminuição de $49,7 \%$ nas aposentadorias concedidas (Tabela 1), em comparação à faixa etária anterior. Isto deve-se ao fato de que, a partir desta idade, a quantidade de pessoas idosas aposentadas começa a diminuir, embora seja possível observar uma tendência crescente ao longo dos anos da população idosa aposentada, concordando com o envelhecimento populacional. Do total de aposentadorias concedidas no período dos cinco anos (13.537), na Paraíba, verifica-se que $59,8 \%$ (8.093) destinaram-se às pessoas com mais de 50 anos.

Cada vez mais cedo trabalhadores economicamente ativos se ausentam do mercado de trabalho por apresentar dificuldades na saúde. Isso revela um grande problema, visto que o afastamento das atividades laborais provoca repercussões tanto sociais como econômicas. Sobre o aposentado incidem danos físicos e psicológicos. Sobre o governo recai o valor dos gastos em saúde pública e previdenciária, já que o trabalhador encontra-se incapacitado para desempenhar suas atividades e está condicionado a benefícios previdenciários. Com a esperança de vida aumentando, surge um novo elenco de demandas para atender às necessidades específicas deste grupo, principalmente relacionadas às DCNTs, e o Brasil ainda não está preparado para receber tal atribuição.

Gomes, Fígoli e Ribeiro (2010), estudando o período 1999-2002, descrevem que as doenças do aparelho circulatório foram a principal causa de concessão de aposentadoria por invalidez no Brasil, representando $29,2 \%$ dos benefícios, seguidas pelas doenças osteomusculares $(19,5 \%)$ e mentais $(12,4 \%)$.

Em Recife-PE, pesquisa realizada por Moura, Carvalho e Silva (2007), para o período 2000-2002, aponta que as principais causas das doenças do aparelho circulatório são as doenças cerebrovasculares e das doenças osteomusculares são as artroses. Após quase uma década, observam-se semelhanças com o presente estudo, com exceção do fato de que, no estudo citado, as neoplasias digestivas tiveram um predomínio, enquanto no atual os cânceres de mama, próstata e colo do útero foram destaque.

Nos resultados deste artigo, foi identificada uma predominância das DCNTs entre 
as quatro primeiras causas para concessão da aposentadoria: doenças do aparelho circulatório; doenças do sistema osteomuscular e do tecido conjuntivo; neoplasias; transtornos mentais e comportamentais, somando $64,5 \%$ dos benefícios concedidos. Este quadro pode se tornar ainda mais crítico, pois com a crescente redução da mortalidade precoce e, em consequência, o aumento do envelhecimento populacional, a prevalência das doenças crônicas deve aumentar, assim como a repercussão na Seguridade Social.

Durante o período pesquisado (20072011), houve uma tendência regular da ordem das causas de aposentadoria, a não ser pelos transtornos mentais e lesões por consequência das causas externas, que em 2009 e 2011 se alternaram. Doença do aparelho circulatório, que é a primeira causa e a mais preocupante, mostra-se declinante, podendo já ser efeito de políticas públicas e programas de saúde destinados a este público.

\section{Considerações finais}

No decorrer da pesquisa, foi possível alcançar os objetivos propostos, traçando o perfil do beneficiário do INSS aposentado por invalidez, entre 2007 e 2011, na Paraíba,

\section{Referências}

ALCÂNTARA, M. A.; NUNES, G. S.; FERREIRA, B. C. M. Distúrbios osteomusculares relacionados ao trabalho: o perfil dos trabalhadores em benefício previdenciário em Diamantina (MG, Brasil). Ciênc. Saúde Coletiva, v. 16, n. 8, p. 3427-3436, 2011.

BATTISTOTTI, M. S. Aposentadoria por invalidez: análise de sua concessão à luz do regime geral de previdência e mais normas aplicáveis à espécie. Trabalho de Conclusão de Curso, Universidade Vale do Itajaí, Tijucas (SC), 2008.

BEZERRA, J. R.; SILVA, M. V.; PEREIRA, M. Z. C.; CRUZ, T. J. Currículo e as relações de gêneros: o olhar de pedagogas de uma escola pública da Paraíba. Espaço do Currículo, v. 4, n. 1, p. 66-77, 2011. e auxiliando a detectar onde se situa a maior parte dos aposentados, para encontrar soluções de promoção à saúde, reabilitação e readaptação dos indivíduos no mercado de trabalho formal.

Como observado, o padrão de causas de concessão de aposentadorias por invalidez tem se modificado, o que causa implicações sobre o protótipo e os níveis de morbidade dos beneficiários. A primeira sugestão de trabalho futuro é a replicação periódica deste estudo, de modo que se possam obter as prováveis morbidades que causem invalidez para realização de promoção à saúde e prevenção de doenças.

Neste sentido, impõe-se como de fundamental importância a realização de estudos multicêntricos para identificar quais os determinantes desta elevada prevalência das DCNTs na população brasileira, com a finalidade de facilitar o planejamento, a gestão, a avaliação e o monitoramento dos programas de vigilância à saúde e na atenção básica.

Espera-se que o conhecimento do padrão de causas de concessão das aposentadorias por invalidez também possa ser útil no planejamento de políticas públicas de prevenção de invalidez e de reabilitação dos trabalhadores.

BRASIL. Ministério da Previdência Social. Anuário Estatístico da Previdência Social - AEPS 2010. Disponível em: < http:// www.mpas.gov.br/conteudoDinamico. php?id=423> Acesso em: 02 ago. 2012.

Aposentadoria por invalidez. Disponível em: <http://www.previdencia. gov.br/conteudoDinamico. php?id=18> Acesso em: 02 ago. 2012.

CEZÁRIO, A. C. Hipertensão arterial e doenças cardiovasculares como causas de concessão de aposentadoria por invalidez no Brasil. Dissertação (Mestrado) - Universidade Federal da Bahia, Salvador (BA), 2008.

COSTA, V. F. I. D. A aposentadoria por inva- 
lidez. Rev. Disc. Jur. Campo Mourão, v. 3, n. 1, p. 143-185, 2007.

ETO, F. N.; SCARPI, J. A.; OLIVEIRA, E. R. A.; GOMES, M. J. Estudo sobre a qualidade de vida de uma amostra de idosos do município de Vila Velha-ES. Rev. Bras. Pesqui. Saúde, v. 12 , n. 4, p. 5-12, 2010.

FERREIRA, N. V. Perfil da aposentadoria por invalidez em servidores públicos municipais do Rio de Janeiro de 1997 a 2008. Dissertação (Mestrado) - Escola Nacional de Saúde Pública Sergio Arouca, Rio de Janeiro (RJ), 2010.

FILHO, N. M.; SILVA, G. A. Invalidez por dor nas costas entre segurados da Previdência Social do Brasil. Rev. Saúde Pública, v. 45, n. 3, p. 494-502, 2011.

GOMES, M. M. F.; FÍGOLI, M. G. B.; RIBEIRO, A. J. F. Da atividade à invalidez permanente: um estudo utilizando dados do Regime Geral de Previdência Social (RGPS) do Brasil no período 1999-2002. Rev. Bras. Estud. Popul., v. 27, n. 2, p. 297-316, 2010.

ILDEFONSO, S. de A. G.; BARBOSA-BRANCO, A.; ALBUQUERQUE-OLIVEIRA, P. R. Prevalência de benefícios de seguridade social temporários devido a doença respiratória no Brasil. J. Bras. Pneumol., v. 35, n. 1, p. 44-53, 2009.

MARRI, I. G.; WAJNMAN, S.; ANDRADE, M. V. Reforma da Previdência Social: simulações e impactos sobre os diferenciais de sexo. Rev. Bras. Estud. Popul., v. 28, n. 1, p. 37-56, jun. 2011.

MEDRONHO, R. A. et al. Epidemiologia. São Paulo: Atheneu, 2006.

MOURA, A. A. G.; CARVALHO, E. F.; SILVA, N. J. C. Repercussão das doenças crônicas não-transmissíveis na concessão de benefícios pela previdência social. Ciênc. Saúde Coletiva, v. 12, n. 6, p. 1661-1672, 2007.

OMS - Organização Mundial da Saúde. Classificação Estatística Internacional de Doenças e Problemas Relacionados à Saúde - Décima Revisão, versão 2008. Disponível em <http://www.datasus.gov.br/ cid10/V2008/WebHelp/cid10.htm> Acesso em: 02 ago. 2012.

PAULA, A. C. S. F.; BUBACH, S.; VELTEN, A. P. C. Análise da mortalidade por doenças do aparelho circulatório no período de 1999 a 2008, no município de São Mateus/ ES. Rev. Bras. Pesqui. Saúde, v. 13, n. 3, p. 28-35, 2011.

SANDI, R. D.; HERINGER, L. P. A previdência social nos municípios do Semi-Árido brasileiro. Informe de Previdência Social, v. 13, n. 8, p. 1-16, 2001.

SIANO, A. K.; RIBEIRO, L. C.; SANTIAGO, A. E.; RIBEIRO, M. S. Influência de alterações normativas da Previdência Social sobre o perfil de concessão de auxílio-doença relativo a transtornos mentais. Ciênc. Saúde Coletiva, v. 16, n. 4, p. 2189-2198, 2011.

\section{Resumen}

Perfil socioeconómico-demográfico del beneficiario del Instituto Nacional de la Seguridad Social, jubilado por invalidez, y sus causas, en el Estado de Paraíba, durante el quinquenio 2007-2011

La jubilación por invalidez provoca un impacto limitador en el crecimiento de la fuerza de trabajo. Este artículo procura trazar el perfil socioeconómico-demográfico del beneficiario jubilado por invalidez, en Paraíba, durante el quinquenio 2007-2011 y verificar la proporción de beneficios concedidos y sus causas. Para ello, fue realizada una investigación observacional, descriptiva, con datos secundarios, a partir de un formulario construido para la recogida de datos, conteniendo las siguientes variables: año en que el beneficio fue concedido; motivo del alejamiento según el Código Internacional de Enfermedades (10ª Revisión); franja de edad, sexo y franja salarial del jubilado tras la invalidez; tiempo de contribución al INSS (Instituto Nacional de la Seguridad Social) antes de la jubilación; y forma de filiación (desempleado, asegurado especial, autónomo, facultativo, empleado doméstico y trabajador ocasional). Para el análisis, 
se utilizó el software Statistical Package for Social Sciences (SPSS), versión 20.0. Del total de 13.537 beneficiarios por invalidez, 62,8\% estaban en la franja de 40 a 59 años, un $64 \%$ eran de sexo masculino, un $63 \%$ poseían una media salarial entre uno y dos salarios mínimos, un $28,3 \%$ de los beneficios fueron concedidos a personas desempleadas y un $25,3 \%$ de las concesiones se debieron a enfermedades circulatorias. Se espera que este estudio sea propulsor de otros estudios en el Estado de Paraíba, puesto que la medición de indicadores es necesaria para que se pueda intervenir en la reducción de las jubilaciones por invalidez.

Palabras-clave: Beneficios de la jubilación. Beneficios del seguro. Invalidez.

\begin{abstract}
Socioeconomic-demographic profile of beneficiaries of the National Social Security Institute, retired to due to disability and their causes, in the State of Paraíba, 2007-2011
\end{abstract}

Retirement due to disability causes a limiting impact on the growth of the labor force. This article seeks to draw the socioeconomic-demographic profile of beneficiaries retired due to disability, in Paraíba, in the 2007-2011 five-year period, and check the proportion of benefits given and their causes. Toward that end, an observational, descriptive survey, with secondary data was performed, using a form developed to collect data, with the following variables: year benefit was granted; reason for leave according to the International Classification of Diseases (10th Revision); age group, gender and wage range of the retired individual after disability; period of contribution to INSS (social security) before retirement; and type of affiliation (unemployed, special insurance, self-standing, non-work related contribution, domestic employee and temporary worker). For the analysis, the Statistical Package for Social Sciences (SPSS) software, version 20.0 was used. Of the total of 13,537 beneficiaries due to disability, $62.8 \%$ were in the 40 to 59 year old group, $64 \%$ were male, $63 \%$ had a mean wage between one and two minimum wages, $28.3 \%$ of benefits were granted to unemployed individuals, and $25.3 \%$ of concessions were due to circulatory conditions. The present study expects to be a driver for other studies in the State of Paraíba, because indicators need to be measured in order to develop interventions to reduce retirements due to disability.

Keywords: Retirement benefits. Insurance benefits. Disability.

Recebido para publicação em 21/06/2012

Aceito para publicação em 08/07/2012 
